\title{
Ni/n-GaAs ve NiO/n-GaAs Diyotların Elektriksel Parametreleri Arasındaki İlişki
}

\author{
Abdullah ÖZKARTAL ${ }^{1 *}$, Dheyab THAER NOORİ ${ }^{2}$ \\ ${ }^{1}$ Van Yüzüncü Yıl Üniversitesi, Fen Fakültesi, Fizik Bölümü, Van \\ ${ }^{2}$ Van Yüzüncü Yıl Üniversitesi, Fen Bilimleri Enstitüsü, Fizik Anabilim Dal,, Van \\ (ORCID: 0000-0002-1556-6141) (ORCID: 0000-0003-2856-9883)
}

\begin{abstract}
$\ddot{\mathbf{O} z}$
$\mathrm{Bu}$ çalışmada, $\mathrm{Ni} / n$-GaAs Schottky ve $p-N i O / n$-GaAs heteroeklem diyotları termal buharlaştırma yöntemi ile üretilmiştir. Üretilen numunelerin elektriksel özellikleri karanlıkta ve oda sıcaklığında, akım-voltaj $(I-V)$ ve kapasitans-voltaj $(C$ - $V)$ ölçümleri ile incelenmiştir. Üretilen numunelerin idealite faktörü $(n)$, engel yüksekliği $\left(\Phi_{b}\right)$ ve seri direnci $\left(R_{s}\right), I-V$ ve $C$ - $V$ ölçümlerinden ayrı ayrı hesaplanmıştır. Ayrıca Cheung fonksiyonları yardımıyla da $n, \Phi_{b}$ ve $R_{s}$ hesaplanarak sonuçların kararlılığı tespit edilmiştir. Schottky diyot yapısının, $p-n$ diyot yapısından daha iyi idealite faktörüne ve daha düşük engel yüksekliğine sahip olduğu belirlenmiştir.
\end{abstract}

Anahtar kelimeler: $\mathrm{Ni} / \mathrm{GaAs}$ Schottky diyot, $\mathrm{NiO} / \mathrm{n}$-GaAs, $\mathrm{NiO}$ ince film, termal buharlaştırma.

\section{Relationship Between Electrical Parameters of $\mathrm{Ni} / \mathrm{n}-\mathrm{GaAs}$ and $\mathrm{NiO} / \mathrm{n}-\mathrm{GaAs}$ Diodes}

\begin{abstract}
In this study, $\mathrm{Ni} / \mathrm{n}$-GaAs Schottky diode and $\mathrm{p}-\mathrm{NiO} / \mathrm{n}$-GaAs heterojunction diodes were produced by thermal evaporation method. The electrical properties of the produced samples were examined by current-voltage $(I-V)$ and capacitance-voltage $(C-V)$ measurements in the dark and at room temperature. The ideality factor $(n)$, barrier height $\left(\Phi_{b}\right)$ and series resistance $\left(R_{s}\right)$ of the produced samples were calculated separately from $I-V$ and $C$ - $V$ measurements. In addition, the stability of the results was determined by calculating $n, \Phi_{b}$ and $R_{s}$ with the help of Cheung functions. It was determined that the Schottky diode structure has a better ideality factor and lower barrier height than the $p$ - $n$ diode structure.
\end{abstract}

Keywords: $\mathrm{Ni} / \mathrm{GaAs}$ Schottky diode, $\mathrm{NiO} / \mathrm{n}-\mathrm{GaAs}, \mathrm{NiO}$ thin film, thermal evaporation.

\section{Giriş}

Elektronikte ve optoelektronikte çok önemli ve geniş kullanım alanı bulunan diyotlar üzerinde çeşitli araştırmalar yoğun bir şekilde sürdürülmektedir [1-7]. Metal oksit ince filmler de özellikle güneş pilleri üretiminde, yariiletken ve 1 şı̆̆ı geçirgen yapısıyla diyot yapılarında pencere materyali olarak kullanılmaktadır. $\mathrm{NiO}, \mathrm{ZnO}, \mathrm{CuO}, \mathrm{SnO}_{2}$ ve ITO gibi metal oksit ince filmler, fotovoltaik ve fotodiyot etkili yapılarda yaygın bir şekilde kullanılmaktadır. $\mathrm{NiO}$ ince filmi de 3.2-4.0 eV arasında yasak enerji bant aralı̆̆ına sahip, $p$ tipi yariletken özellik taşıyan şeffaf önemli bir pencere materyalidir. NiO, antiferromanyetik kararlı yapısı ile güneş pilleri, gaz sensörleri, elektrokromik cihaz, fotoelektroliz gibi birçok farklı elektronik cihazda kullanılma imkânına sahiptir [8-14].

Bilindiği gibi ince filmler sol-jel, püskürtme yöntemi (spray pyrolysis), döndürerek kaplama (spin coating), $r f-d c$ magnetron püskürtme, kimyasal banyo biriktirme, kimyasal işleme, e-ışın buharlaştırma, termal buharlaştırma, PA-MOCVD, daldırmalı kaplama, atomik tabaka biriktirme gibi farklı tekniklerle üretilebilmektedir. $\mathrm{NiO}$ ince filmli cihazların üretiminde de birçok teknik kullanılmıştır

*Sorumlu yazar: abdullahozkartal@yyu.edu.tr

Geliş Tarihi: 14.02.2021, Kabul Tarihi: 16.04.2021 
[15-21]. Bu çalışmada da $p-N i O / n-G a A s$ - $n$ heteroeklem diyotları ve $N i / n-G a A s$ Schottky diyotları termal buharlaştırma yöntemi kullanılarak üretilmiş̧ir [22-23].

$\mathrm{Ni} / n$-GaAs Schottky diyotları daha önce farklı üretim yöntemleriyle üretilmiş ve elektriksel karakteristikleri incelenmiştir [24-29]. p-NiO/n-GaAs heteroeklem diyot da daha önce sol-jel yöntemi ile üretilmiş ve elektriksel özellikleri belirlenmiştir [30].

Biz de bu çalışmamızda, basit ve kolay bir yöntem olan termal buharlaştırma yöntemini kullandık. Termal buharlaştırma yöntemi hassas ve basit bir şekilde ince filmin istenen kalınlıkta üretilmesini sağlar. Ayrıca her türlü yüzeyde üretilme imkânı vermesi nedeniyle organik malzemelerle de kolayca kullanılabilmektedir. Termal buharlaştırma yöntemi ile üretilen $N i / n-G a A s$ Schottky diyotların ve $p$-NiO/n-GaAs heteroeklem diyotların elektriksel özellikleri belirlendi ve elektriksel özellikleri arasındaki ilişki yorumlandı.

\section{Materyal ve Metot}

$\mathrm{Ni} / n-\mathrm{GaAs}$ Schottky diyotları ve $p$-NiO/n-GaAs heteroeklem diyotları üretiminde $350 \mu \mathrm{m}$ kalınlığında, $7.3 \times 10^{15} \mathrm{~cm}^{-3}$ taşıyıcı konsantrasyonuna sahip, [100] kristal yöneliminde Si katkılı, $p$ tipi GaAs yarıiletken kristali kullanıldı. GaAs kristali organik ve mekanik kirlerden temizlemek için sırasıyla aseton ve izopropil alkol ile ultrasonik banyo küvetinde yıkandi. Her işlemden sonra deiyonize su ile duruland1. Sonra (5:1:1) oranındaki $\mathrm{H}_{2} \mathrm{SO}_{4}: \mathrm{H}_{2} \mathrm{O}_{2}: \mathrm{H}_{2} \mathrm{O}$ çözeltisine $1 \mathrm{dk}$ süre ile daldırıldı ve deiyonize su ile durulandı. Daha sonra doğal olarak oluşabilecek oksit tabakasından kurtulmak için $(1: 1)$ oranındaki $\mathrm{HCl}: \mathrm{H}_{2} \mathrm{O}$ çözeltisine $5 \mathrm{~s}$ süresince daldırıldı ve deiyonize su ile durulandıktan sonra yüksek saflıktaki nitrojen $\left(N_{2}\right)$ gazı ile kurutuldu [31]. GaAs kristali kurutulur kurutulmaz yeni oksit tabaksı oluşmaması için çok hızlı bir şekilde vakumda kaplama cihazına (Edwards Auto, model-306) yerleştirildi.

Vakumda kaplama cihazındaki basınç $1.33 \times 10^{-6} \mathrm{kPa}$ a düştüğünde \%99.9 saflıktaki altın $(\mathrm{Au})$ metali $15 \mathrm{~mm}$ x $30 \mathrm{~mm}$ yüzey alana sahip $n-G a A s$ kristalinin mat yüzeyine buharlaştırıldı. $A u$ ile kaplanan numune vakum cihazından çıkarıldı ve omik kontak olması için $450^{\circ} \mathrm{C}$ sıcaklığında ve nitrojen ortamındaki kuvars cam firında $5 \mathrm{dk}$ süre ile isıl tavlama yapıldı [32].

$A u$ ile omik kontağ yapılmış $n$-GaAs kristali $15 \mathrm{~mm}$ x $15 \mathrm{~mm}$ yüzey alanına sahip iki parçaya ayrıld1. Birinci numuneye, $\mathrm{p}-\mathrm{NiO} / \mathrm{n}-\mathrm{GaAs}$ heteroeklem diyot oluşturmak için nanotoz halindeki \%99.9 saflıktaki nikel (II) oksit tozu vakum kaplama cihazında buharlaştırıldı. Aynı şekilde ikinci numuneye de $N i / n-G a A s$ Schottky diyot oluşturmak için yine toz halinde ve \%99.9 saflıktaki nikel metali buharlaştırıld1. \%99.9 saflıktaki nikel (II) oksit ve nikel tozları Sigma Aldrich' ten temin edilmiştir. 2 mm çapında maskeler kullanılarak oluşturulan bu diyotların kalınlığı 200 nm civarındadır. Kalınlıklar vakumda kaplama cihazındaki kalınlık tespit sistemi ile belirlenmiştir.

$p$-NiO/n-GaAs p- $n$ heteroeklem diyotları ve Ni/n-GaAs Schottky diyotların akım-voltaj (I-V) ölçümleri Keithley (model 6487) pikoampermetre/voltaj kaynağı kullanılarak karanlıkta ve oda sıcaklığında alınmıştır. Üretilen numunelerin şematik gösterimi Şekil 1'de verilmiştir.

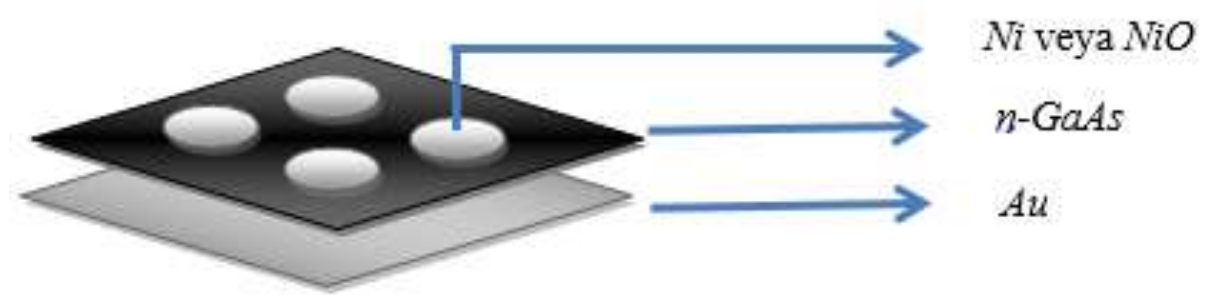

Şekil 1. $p-N i O / n-G a A s / A u$ ve $N i / n-G a A s / A u$ yapıların şematik gösterimi.

\section{Bulgular ve Tartışma}

Üretilen numunelerin $I$ - $V$ karakteristikleri literatürde Termiyonik Emisyon (TE) teorisine göre açıklanmaktadır. Bu teoriye göre, bir diyot için ideal olmayan şartlarda düz besleme akımı şu şekilde ifade edilmektedir [33]. 


$$
I=I_{0}\left[\exp \left(-\frac{e\left(V-I R_{S}\right)}{n k T}\right)-1\right]
$$

Burada $n$, idealite faktörü; $k$, Boltzmann sabiti; $T$, Kelvin cinsinden oda sicaklığı; $e$, elektronun yükü ve $V$, diyota düz besleme olarak uygulanan voltaj; $R_{s}$, seri direnç ve $I_{0}, \mathrm{~V}=0$ ' da $\ln I$ eksenini düz çizgi kesişiminden elde edilen doyma akımıdır. Diyotların $I-V$ grafikleri Şekil 2'de verilmiştir.

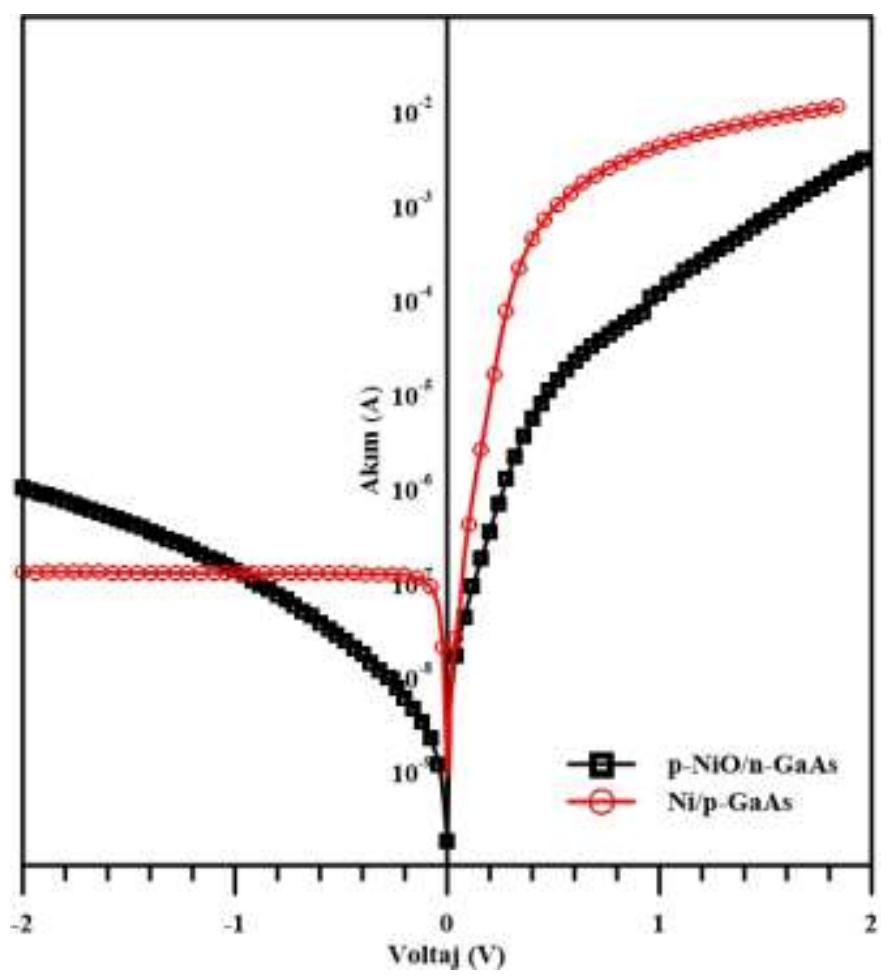

Şekil 2. $p-N i O / n-G a A s / A u$ ve $N i / n-G a A s / A u$ diyotların $\operatorname{lnI-V}$ grafikleri

$$
I_{0}=A R^{*} T^{2} \exp \left(-\frac{e \Phi_{b}}{k T}\right)
$$

Denklem 2'deki $R^{*}$, değeri $n$-GaAs yariiletkeni için $8.16 \mathrm{~A} / \mathrm{cm}^{2} \mathrm{~K}^{2}$ olan Richardson sabitidir [30]; $A$, yarıçapı $1 \mathrm{~mm}$ olan etkin diyot alanıdır; $\Phi_{b}$, diyodun engel yüksekliğidir.

$$
n=\frac{e}{k T} \frac{d V}{d(\ln I)}
$$

İdealite faktörü $n, \operatorname{lnI-V}$ grafiğinin düz beslem kısmındaki eğimin fitinden elde edilerek Denklem 3 yardımıyla hesaplanır. İdealite faktörü metal-yarıiletken kontaklarda 1 değerine oldukça yakın olması beklenir. Bununla birlikte $p$ - $n$ heteroeklem diyotlarda idealite faktörünün 1 değerinden oldukça uzak olmasını arayüzey durumlarına, seri direncin büyüklügüne ve arayüzey tabakalarına atfedilir. Burada da ön görüldüğü gibi $\mathrm{Ni} / \mathrm{n}$-GaAs Schottky diyotların idealite faktörü 1.06; $p$-NiO/nGaAs p- $n$ heteroeklem diyotların idealite faktörü 2.04 olarak hesaplanmıştır. Bu kadar yüksek idealite faktörünü $p-N i O / n-G a A s$ arayüzeyindeki doğal yoğun oksidasyona atfedilebilir [25].

$$
e \Phi_{b}=k T \cdot \ln \left(\frac{A R^{*} T^{2}}{I_{0}}\right)
$$

Diyotların engel yükseklikleri $\Phi_{b}$, Denklem 4. yardımıyla hesaplanmaktadır. $N i / n-G a A s$ Schottky diyotların engel yüksekliği $0.70 \mathrm{eV} ; \mathrm{p}-\mathrm{NiO} / n-\mathrm{GaAs} p$ - $n$ heteroeklem diyotların engel yüksekliği $0.75 \mathrm{eV}$ olarak hesaplanmıştır. 
Bununla birlikte, diyotların idealite faktörü, engel yükseklikleri ve seri direnç değerleri Cheung ve Cheung yöntemi ile hesaplama yapılarak sonuçların kararlılı̆̆ desteklenmiştir [36]. Bu fonksiyonlar Denklem 5 ve Denklem 6'da verilmiştir;

$$
\begin{aligned}
& \frac{d V}{d(\ln I)}=\frac{n k T}{e}+I R_{S} \\
& H(I)=n \Phi_{b}+I R_{S}
\end{aligned}
$$

Denklem 5 ve Denklem 6'ya göre idealite faktörü,bariyer yüksekliği ve seri dirençleri Şekil 3 'deki $d V / d(\ln I)$-I grafiklerinden ve Şekil 4'deki $H(I)$-I grafiklerinden elde edilmiştir. Üretilen diyotların bu grafiklerden elde edilen elektriksel parametrelerin deneysel değerleri Tablo 1'de verilmiştir.

Tablo 1. $p-N i O / n-G a A s$ ve $N i / n-G a A s$ diyotların elektriksel parametrelerin deneysel değerleri

\begin{tabular}{cccccccc}
\hline Örnekler & $n$ & $n$ & $\Phi_{b}(e V)$ & $\Phi_{b}(e V)$ & $\Phi_{b}(e V)$ & $R_{S}(\Omega)$ & $R_{S}(\Omega)$ \\
& $(I-V)$ & $($ Cheung $)$ & $(I-V)$ & $($ Cheung $)$ & $(C-V)$ & $(d V / d l n I)-I$ & $(H(I)-I)$ \\
\hline$N i / n-G a A s$ & 1.06 & 1.21 & 0.70 & 0.69 & 0.76 & 141 & 164 \\
NiO/n-GaAs & 2.04 & 2.81 & 0.75 & 0.71 & 0.71 & 6296 & 7072 \\
\hline
\end{tabular}

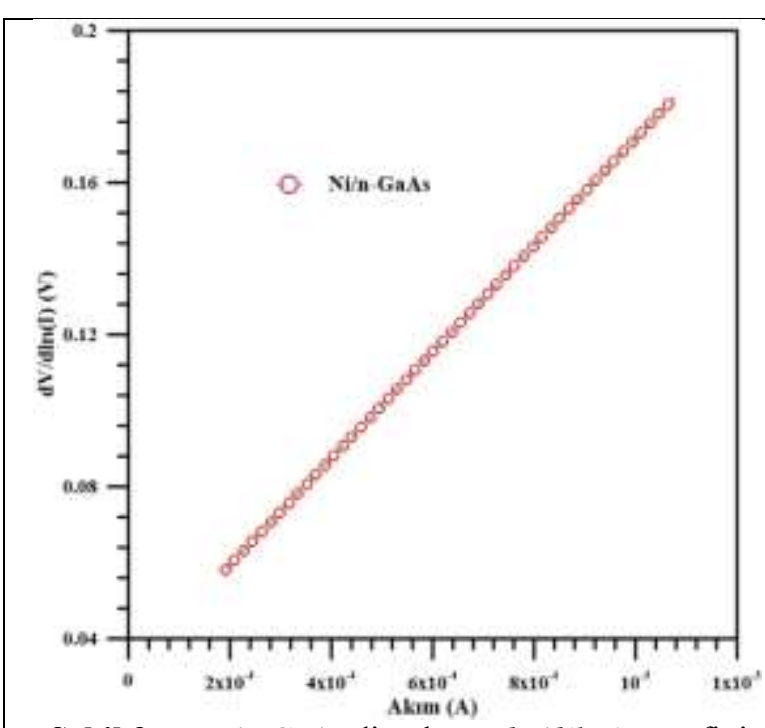

Şekil 3-a. $N i / n-G a A s$ diyotların $d V / d(\ln I)-I$ grafiğgi

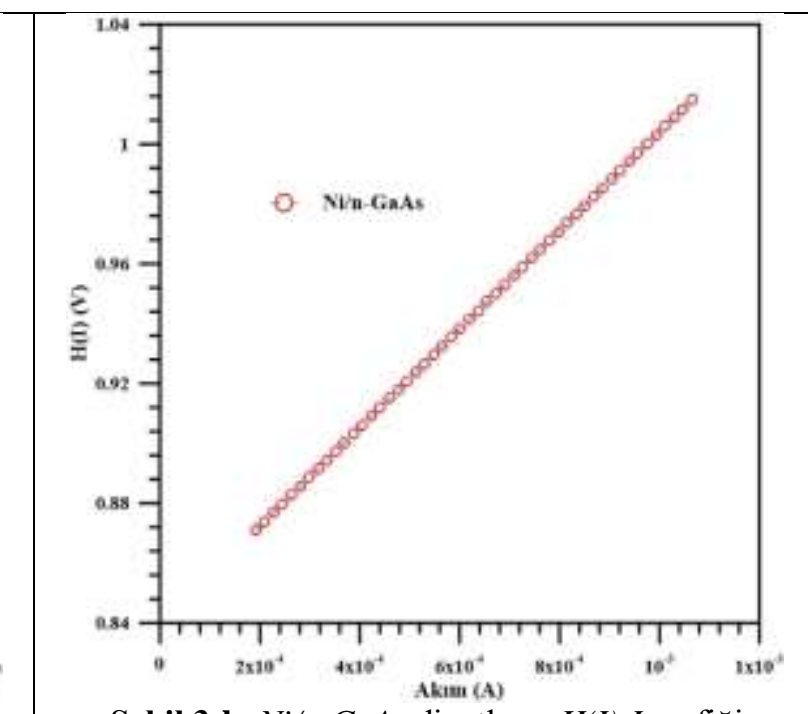

Şekil 3-b. Ni/n-GaAs diyotların $H(I)-I$ grafiği

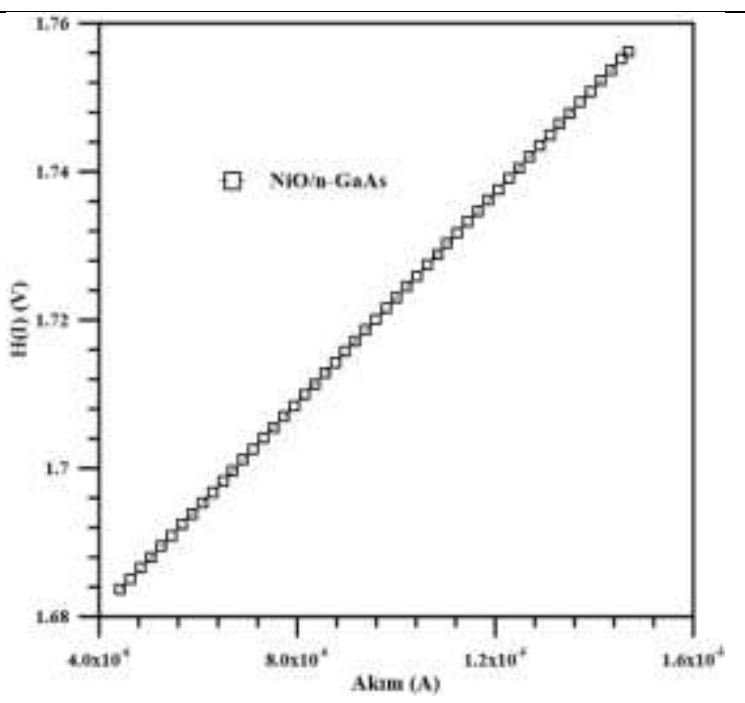

Şekil 4-b. $N i O / n-G a A s$ diyotların $H(I)-I$ grafiği

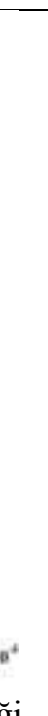

Şekil 4-a. $N i O / n-G a A s$ diyotların $d V / d(\operatorname{lnI})-I$ grafiği

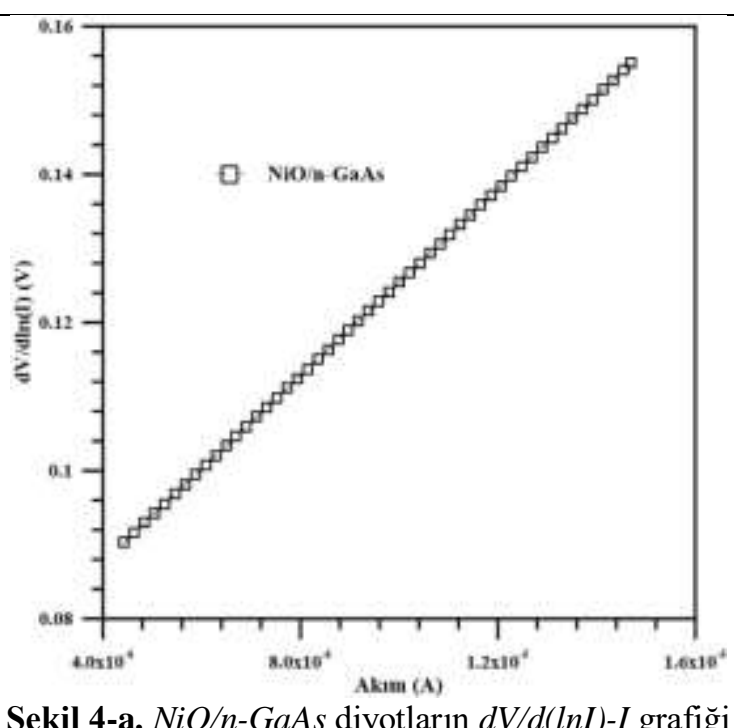

(3) 
Doğrultucu özelliğe sahip bir kontağın elektriksel özelliklerini karakterize eden en temel ölçümlerinden biri de kapasitans-voltaj $(C$-V $V$ ölçümüdür. Üretilen diyotların oda sıcaklığında ve 100 $\mathrm{kHz}$ sabit frekansta ölçülen $C$-V grafiği Şekil 5 'te verilmiştir. $C$ - $V$ ölçümünden elde edilen $C^{-2}-V$ grafiği de Şekil 6'da verilmiştir.

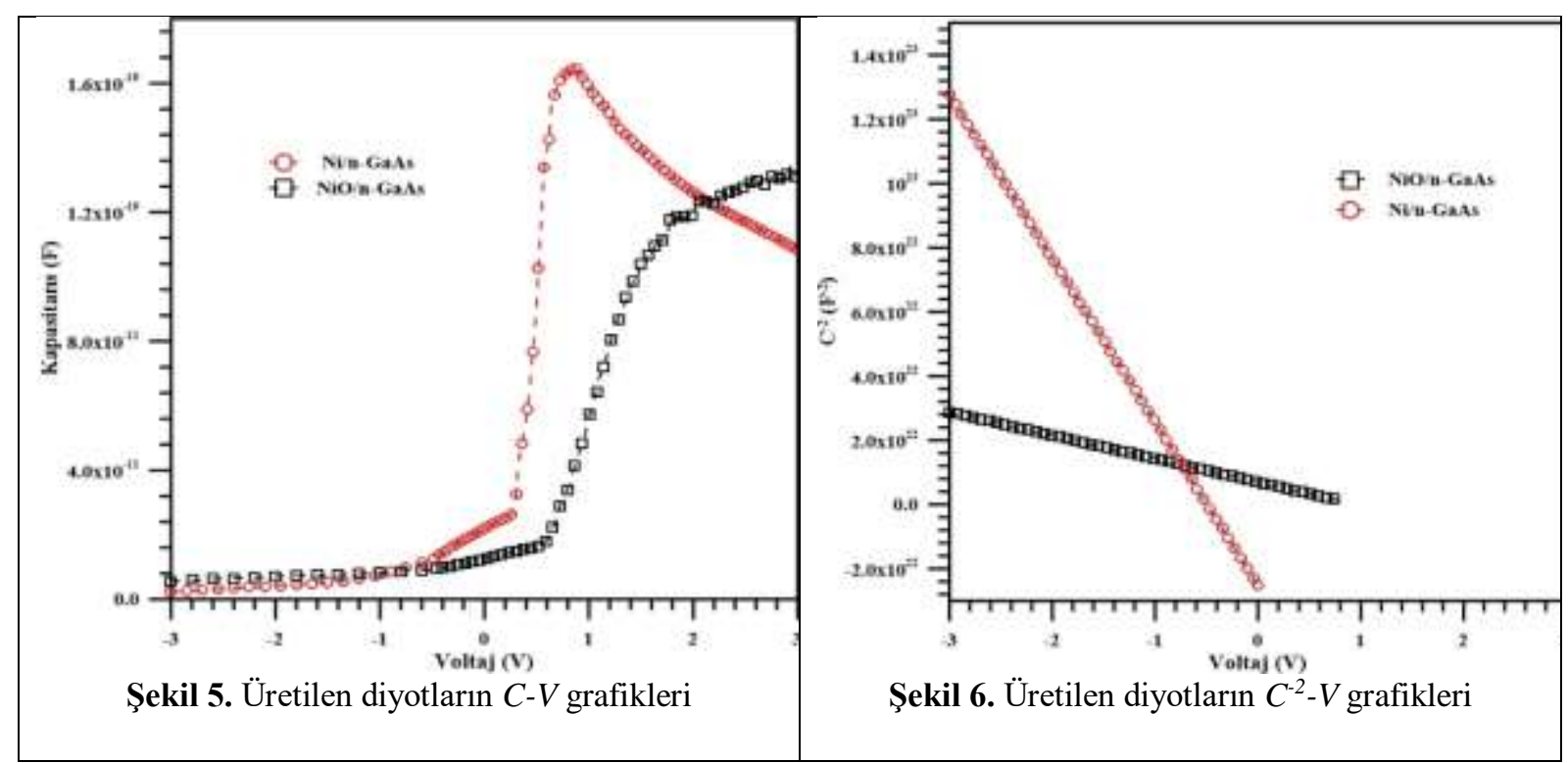

Şekil 5'te, $-3 \mathrm{~V}$ ile $+3 \mathrm{~V}$ aralığında $p$-NiO/n-GaAs p-n heteroeklem ve $N i / n-G a A s$ Schottky diyotların $C$ - $V$ ölçümünün düz besleme bölgesi gösterilmektedir. Şekil 5 'ten de görüldüğü gibi düz beslem bölgesinde artan voltaj ile kapasitanslarında kendi diyot karakterlerine uygun olarak artmıştır. Tüm diyotlar genel olarak ölçülen kapasitansları uygulanan voltaja ve frekansa bağımlılık gösterir. Kapasitansın voltaja ve frekansa bağlılı̆g üretim şartlarında oluşan kirlilik derecelerine, yüksek seri dirence, arayüzey durumlarına ve arayüzey katmanları gibi diyotların belirli özelliklerinden kaynaklanmaktadır.

Şekil 6'da üretilen diyotların ters beslemedeki $C^{-2}-V$ grafiğinin bir doğrusal olduğu görülmektedir. Bu doğrusallık Schottky diyot ile uyumlu olduğunu ve arayüzey tabakası teorisi ile açıklanabilmektedir [34]. Doğrultucu kontaklarda, arayüzey katmanı kapasitansı Denklem 7 ile verilmektedir.

$$
C^{-2}=\frac{2\left(V_{d}-V\right)}{q \varepsilon_{s} \varepsilon_{0} A^{2} N_{d}}
$$

Burada $V_{d}, C^{-2}-V$ grafiğinin doğrusal kısmından elde edilen sıfır gerilimdeki difüzyon potansiyelidir; $V$, diyota uygulana gerilimdir; $\varepsilon_{s}, n$-GaAs yariiletkeninin dielektrik sabitidir ve değeri 13.2'dir [29]; $\varepsilon_{0}$, boşluğun dielektrik sabitidir $\left(\varepsilon_{0}=8.85 \times 10^{-12} \mathrm{~F} / \mathrm{m}\right) ; N_{d}$, Si katkl11 $n$-GaAs yariiletkeninde katkılamaya bağlı olarak oluşan donör yoğunluğudur ve Denklem 7 yardımıyla donör yoğunluğu Denklem 8 gibi hesaplanır.

$$
N_{d}=\frac{2}{q \varepsilon_{s} \varepsilon_{0} A^{2}} \frac{1}{\frac{d\left(c^{-2}\right)}{d V}}
$$

$C^{-2}-V$ grafiğinden elde edilen elektriksel parametreler Tablo 2'de verilmiştir.

Tablo 2. Üretilen diyotların $C^{-2}-V$ grafiğinden elde edilen elektriksel parametreleri

\begin{tabular}{ccccc}
\hline Örnekler & $\mathrm{V}_{\mathrm{d}}(\mathrm{V})$ & $\mathrm{E}_{\mathrm{f}}(\mathrm{eV})$ & $\mathrm{N}_{\mathrm{d}}\left(\mathrm{cm}^{-3}\right) \times 10^{13}$ & $\Phi_{\mathrm{b}}(\mathrm{eV})$ \\
\hline $\mathrm{Ni} / \mathrm{n}-\mathrm{GaAs}$ & 0.49 & 0.31 & 0.31 & 0.76 \\
$\mathrm{NiO} / \mathrm{n}-\mathrm{GaAs}$ & 0.96 & 0.25 & 2.63 & 0.71 \\
\hline
\end{tabular}


$C^{-2}-V$ grafiğinin ters besleme kısmından üretilen diyotların engel yüksekliği Denklem 9 yardımiyla hesaplanabilir.

$$
\Phi_{b}=E_{f}+V_{d}
$$

Burada $E_{f}$, Fermi enerji seviyesidir ve Denklem 10. şeklinde hesaplanır.

$$
\mathrm{E}_{f}=k T \ln \left(\frac{N_{c}}{N_{d}}\right)
$$

Burada $N_{c}$, yariiletkenin iletkenlik bandındaki durumların etkin yoğunluğu olarak adlandırılır. $n$-GaAs yarriletken için oda sıcaklığında, $N_{c}=4.7 \times 10^{17} \mathrm{~cm}^{-3}[29]$.

$\mathrm{Bu}$ çalıșmanın amacı, termal buharlaștırma yöntemi ile üretilen $p-\mathrm{NiO} / n-\mathrm{GaAs}$ heteroeklem diyotlar ile Ni/n-GaAs Schottky diyotların elektriksel parametreleri arasındaki ilişkiyi incelemektir. Bu amaçla her iki diyotta aynı şartlarda üretildi. Üretilen numunelerin $I-V$ ve $C$ - $V$ ölçümlerinin grafikleri çizilmiştir. Diyotların hesaplanan elektriksel parametreleri Tablo 1 ve Tablo 2'de gösterilmektedir. Numunelerin idealite faktörleri seri dirençleri ihmal edilerek Denklem 3'e göre $I-V$ grafiğinin düz besleme bölgesindeki doğrusal eğimlerinden hesaplanmıştır. Etkin engel yükseklikleri de Denlem 4. kullanılarak hesaplanmıştır. Schottky diyotta idealite faktörü ideale oldukça yakın 1.06 iken, $p$ - $n$ diyotta arayüzey oksidasyonu ve arayüzey bölgesindeki rekombinasyon nedeniyle 2.04 olarak hesaplanmıştır. Engel yükseklikleri de beklendiği gibi $p$ - $n$ yapısının $0.75 \mathrm{eV}$ ile Schottky yapısındakinden $0.70 \mathrm{eV}$ olarak daha büyük bulundu. Bulunan bu idealite faktörü ve engel yükseklik değerleri literatür ile uyum içindedir [25-28, 30, 37, 38].

Üretilen numunelerin idealite faktörü, engel yükseklikleri ve seri dirençleri Cheung fonksiyonları yardımıyla da hesaplandı. İdealite faktörü ve engel yükseklikleri arasındaki fark Cheung fonksiyonları ile de desteklenmiş oldu. $p$ - $n$ yapısının seri direnci Schottky yapısından oldukça büyük hesaplanmıştır. $100 \mathrm{kHz}$ sabit frekans altında $-3 \mathrm{~V}$ ile $+3 \mathrm{~V}$ arasında ölçülen $C$ - $V$ değerlerinden hesaplanan engel yükseklikleri $p$-NiO/n-GaAs heteroeklem diyotları için $0.71 \mathrm{eV}$ ve $\mathrm{Ni} / \mathrm{n}$-GaAs Schottky diyotları için $0.76 \mathrm{eV}$ olarak hesaplanmıştır. $C$ - $V$ ölçümlerinden elde edilen engel yükseklikleri arasındaki fark, yapısal fark olarak dikkat çekmektedir. Diyot kapasiteleri artan voltaj ile hızla artmakta ve belirli bir değerden sonra neredeyse kararlı hale gelmektedir.

\section{Sonuç ve Öneriler}

Elektriksel parametrelerini hesaplamak ve aralarındaki ilişkiyi belirlemek amacıyla aynı deneysel şartlarda termal buharlaştırma yöntemi ile $p-\mathrm{NiO} / \mathrm{n}-\mathrm{GaAs}$ heteroeklem diyotları ile $\mathrm{Ni} / \mathrm{n}$-GaAs Schottky diyotları üretildi. I-V grafiklerinden $\mathrm{p}$-NiO/n-GaAs heteroeklem diyotları arayüzey bölgesindeki potansiyel engel yüksekliğiyle aynı geleneksel $\mathrm{Ni} / \mathrm{n}$-GaAs Schottky diyotları gibi doğrultma özelliği göstermiştir. p-n yapılarının idealite faktörü 2.04 ve engel yüksekliği $0.75 \mathrm{eV}$ ile geleneksel Schottky yapısındakinden daha büyük olduğu görülmüsşür. Cheung fonksiyonu yardımıyla hesaplanan $p-\mathrm{NiO} / \mathrm{n}$ GaAs heteroeklem diyotların seri dirençleri $6296 \Omega$ ve $7072 \Omega$ ile Ni/n-GaAs Schottky diyotlarından daha büyüktür. C-V ölçümlerinden elde edilen engel yükseklikleri $p$-NiO/n-GaAs heteroeklem diyotları için $0.71 \mathrm{eV}$ ve $\mathrm{Ni} / n-\mathrm{GaAs}$ Schottky diyotları için $0.76 \mathrm{eV}$ olarak hesaplanmıştır. Sonuç olarak, p-n yapısı ile geleneksel Schottky yapısı arasındaki idealite faktörü, engel yüksekliği ve seri direnç gibi elektriksel parametreler arasındaki farklar termal buharlaştırma yöntemi ile üretilerek tespit edilmiş oldu.

\section{Teșekkür}

Bu çalışma, Van Yüzüncü Yıl Üniversitesi Bilimsel Araştırma Projeleri Koordinatörlüğü tarafından FYL-2018-7203 proje numarası ile finansal olarak desteklenmiştir.

\section{Yazarların Katkısı}

Yazarların makaleye olan katkıları eşit orandadır. 


\section{Çıkar Çatışması Beyanı}

Yazarlar arasında herhangi bir çıkar çatışması bulunmamaktadır.

\section{Araştırma ve Yayın Etiği Beyanı}

Yapılan çalışmada araştırma ve yayın etiğine uyulmuştur.

\section{Kaynaklar}

[1] Aydoğan Ş., Grilli M.L., Yilmaz M., Çaldiran Z., Kaçuş H. 2020. A facile growth of spray based $\mathrm{ZnO}$ films and device performance investigation for Schottky diodes: Determination of interface state density distribution. Journal of Alloys and Compounds, 708: 55-66.

[2] Duman S., Ejderha K., Orak I., Yıldırım N., Turut A. 2020. Temperature dependence of interface state density distribution determined from conductance-frequency measurements in $\mathrm{Ni} / \mathrm{n}$ GaAs/Al diode. Journal of Materials Science: Materials in Electronics, 31 (23): 21260-21271.

[3] Kacus H., Yilmaz M., Kocyigit A., Incekara U., Aydogan S., 2020. Optoelectronic properties of $\mathrm{Co} /$ pentacene/Si MIS heterojunction photodiode. Physica B: Physics of Condensed Matter, 597: 412408.

[4] Karataş Ş. 2020. Temperature and voltage dependence C-V and G/w-V characteristics in Au/ntype GaAs metal-semiconductor structures and the source of negative capacitance. Journal of Materials Science: Materials in Electronics, https://doi.org/10.1007/s10854-020-04850-1.

[5] Namini A.S., Asl M.S., Givi G.P., Delbari S.A., Farazin J., Altındal Ş., Kalandaragh Y.A. 2020. On the electrical characteristics of $\mathrm{Al} / \mathrm{p}$-Si diodes with and without (PVP:Sn- $\mathrm{TeO}_{2}$ ) interlayer using current-voltage (I-V) measurements. Applied Physics A, 126935.

[6] Özdemir M.C., Sevgili Ö., Orak İ., Turut A. 2020. Arayüzey doğal oksit tabakalı Al/p-Si/Al yapıların dielektrik karakteristiklerine ölçüm frekanslarının etkileri. Iğdır Üniversitesi Fen Bilimleri Enstitüsü Dergisi, 10 (1): 91-100.

[7] Taha H., İbrahim K., Rahman M.M., Henry D.J., Yin C.Y., Veder J.P., Amri A., Zhao X., Jiang Z.T. 2020. Sol-gel derived ITO based bi-layer and tri-layer thin film coatings for organic solar cells applications, Applied Surface Science, 530: 147164.

[8] Al-Ghamdi A.A., Abdelwahab M.S., Farghali A.A., Hasan P.M.Z. 2016. Structural, optical and photo-catalytic activity of nanocrystalline NiO thin films. Materials Research Bulletin, 75: 71-77.

[9] Chrissanthopoulos A., Baskoutas S., Bouropoulos N., Dracopoulos V., Poulopoulos P., Yannopoulos S.N. 2011. Synthesis and characterization of $\mathrm{ZnO} / \mathrm{NiO}$ p-n heterojunctions: $\mathrm{ZnO}$ nanorods grown on $\mathrm{NiO}$ thin film by thermal evaporation. Photonics and Nanostructures, 9: 132139.

[10] Manjunath V., Bimli S., Parmar K.H., Shirage P.M., Devan R.S. 2019. Oxidized nickel films as highly transparent HTLs for inverted planar perovskite solar cells. Solar Energy, 193: 387-394.

[11] Patel M., Kim H.S., Kim J., Yun J.H., Kim S.J., Choi E.H., Park H.H. 2017. Excitonic metal oxide heterojunction $\mathrm{NiO} / \mathrm{ZnO}$ solar cells for all transparent modüle integration. Solar Energy Materials and Solar Cells, 170: 246-253.

[12] Park S.Y., Kim H.R., Kang Y.J., Kim D.H., Kang J.W. 2010. Organic solar cells employing magnetron sputtered p-type nickel oxide thin film as the anode buffer layer. Solar Energy Materials and Solar Cells, 94: 2332-2336.

[13] Haider A.J., Al-Anbari R., Sami H.M., Haider M.J. 2019. Photocatalytic activity of nickel oxide. Journal of Materials Research and Technology, 8 (3): 2802-2808.

[14] Gupta R.K., Hendi A.A., Cavas M., Al-Ghamdi A.A., Al-Hartomy O.A., Aloraini R.H., ElTantawy F., Yakuphanoglu F. 2014. Improvement of photoresponse properties of $\mathrm{NiO} / \mathrm{p}-\mathrm{Si}$ photodiodes by copper dopant. Physica E, 56: 288-295.

[15] Akinkuade S., Mwankemwa B., Nel J., Meyer W. 2018. Structural, optical and electrical characteristics of nickel oxide thin films synthesised through chemical processing method. Physica B, 535: 24-28. 
[16] Gil M.M., Monroy M.I.P., Leal M.C., German D.C., Fontecha A.G., Lopez M.A.Q., Lerma M.S. 2017. Influence of annealing temperature on nickel oxide thin films grown by chemical bath deposition. Materials Science in Semiconductor Processing. 72: 37-45.

[17] Chen S.C., Wen C.K., Kuo T.Y., Peng W.C., Lin H.C. 2014 Characterization and properties of $\mathrm{NiO}$ films produced by rf magnetron sputtering with oxygen ion source assistance. Thin Solid Films, 572: 51-55.

[18] Wang H., Wu G., Cai X.P., Zhao Y., Shi Z.F., Wang J., Xia X.C., Dong X., Zhang B.L., Ma Y., Du G.T. 2012. Effect of growth temperature on structure and optical characters of NiO films fabricated by PA-MOCVD. Vacuum, 86: 2044-2047.

[19] Gavale H.S., Wagh M.S., Gosavi S.R. 2019. Band gap engineering in spray pyrolysis grown nanocyristalline $\mathrm{NiO}$ thin films by Fe doping. Journal of Nano and Electronic Physics, 11 (4): 04015.

[20] Guillen C., Herrero J. 2019. Transparent and p-type NixO thin films obtained by reactive DC sputtering at room temperature. Materials Research Express, 6: 096410.

[21] Patel K.J., Desai M.S., Panchal C.J., Rehani B. 2011. p-type transparent NiO thin films by e-beam evaporation techniques. Journal of Nano and Electronic Physics, 3 (1): 376-382.

[22] Ozkartal A. 2019. Characterization of the ITO/p-Si/Al contacts produced by thermal evaporation. Vacuum, 168: 108799.

[23] Özmenteş R., Temirci C., Ozkartal A., Ejderha K., Yildirim N. 2018. Characterization of CuO/nSi heterojunction solar cells produced by thermal evaporation. Materials Science-Poland, 36 (4): 668-674.

[24] Jayavel P., Santhakumar K., Kumar J. 2002. Studies on the proton irradiation induced defects on $\mathrm{Ni} / \mathrm{n}-\mathrm{GaAs}$ Schottky barrier diodes. Physica B, 315: 88-95.

[25] Doğan H., Korkut H., Yıldırım N., Turut A. 2007. Prediction of lateral barrier height in identically prepared Ni/n-type GaAs Schottky barrier diodes. Applied Surface Science, 253: 7467-7470.

[26] Melebaev D., Melebaeva G.D., Rud V.Y., Rud Y.V. 2009. Photosensitivity of the Ni/n-GaAs Schottky barriers. Semiconductors, 43 (1): 29-32.

[27] Aldemir D.A., Kökce A., Özdemir Ö.F. 2012. Temperature dependent ideality factor and barrier height of Ni/n-GaAs/In Schottky diodes. Microelectronic Engineering, 98: 6-11.

[28] Bobby A., Shiwakoti N., Sarun P.M., Verma S., Asokan K., Antony B.K. 2015. Swift heavy ion induced capacitance and dielectric properties of Ni/n-GaAs Schottky diode. Current Applied Physics, 15: 1500-1505.

[29] Guzel A., Duman S., Yıldırım N., Turut A. 2016. Electronic transport of an Ni/n-GaAs diiode analysed over a wide temperatur range. Journal of Electronic Materials, 45 (6): 2008-2014.

[30] Turgut G., Duman S. 2016. Sol-gel growth and characterization of a new p-NiO/n-GaAs structure. Journal of Alloys and Compounds, 664: 547-552.

[31] Nuhoğlu Ç., Temirci C., Bati B., Biber M., Türüt A. 2000. Effect of thermal annealing on Co/nLEC GaAs (Te) Schottky contacts. Solid State Communications, 115: 291-295.

[32] Akın B., Altındal Ş., 2020. On the frequency and voltage dependent main electrical parameters of the $\mathrm{Au} / \mathrm{ZnO} / \mathrm{n}-\mathrm{GaAs}$ structures at room tempereture by using various methods. Physica $\mathrm{B}$ : Physics of Condensed Matter, 594: 412274.

[33] Ziel A. 1968. Solid State Physical Electronics. Second ed., Prentice-Hall, New Jersey.

[34] Sze S.M. 1981. Physics of Semiconductor Devices. Second ed., Wiley, New York.

[35] Rhoderick E.H., Williams R.H. 1978. Metal-Semiconductor Contacts. Oxford University Press.

[36] Cheung S.K., Cheung N.W. 1986. Extraction of Schottky diode parameters from forward currentvoltage characteristics. Applied Physics Letters, 49 (2): 85-90.

[37] Nathan M., Shoshani Z., Askinazi G., Meyler B., Zolotarevski O. 1996. On the temperature dependence of the barier height and the ideality factor in high voltage Ni/n-GaAs Schottky diodes. Solid-State Electronics, 39: 1457-1462.

[38] Newman N., Schilfgaarde M., Kendelwicz T., Williams M.D., Spicer W.E. 1986. Electrical study of Schottky barriers on atomically clean GaAs(110) surface. Physical Review B, 33 (2): 11461159. 